\title{
Using Wikipedia as a classroom tool - a translation experience
}

\section{Martínez Carrasco, Robert}

Department of Translation and Interpretation, Universitat Jaume I, Spain

\begin{abstract}
This paper presents a classroom experience regarding the use of Wikipedia in a teaching innovation project carried out between Jaume I University and Wikimedia Spain. Framed in the current post-postivist climate within the European Higher Education Area (EHEA), Wikipedia will be presented as an inter-disciplinary tool with a relevant number of classroom applications, reflecting how meaningful learning experiences based on collaborative work and authentic project-based tasks lead to better understanding and higher levels of motivation among the students. In the particular case of translation education, it will be argued that using Wikipedia in the course of the reverse translation modules allows the students to gain a deeper insight of its linguistic and discursive structures, as well as the critical/exegetic skills they need in order to assess the kind of texts with which they are commissioned, and the special discursive techniques associated to the translation task.
\end{abstract}

Keywords: Wikipedia, translation pedagogy, project-based learning, higher education 


\section{Framing Education on Institutional and Epistemological Terms}

The situated, context-bound nature of Education (Risku, 2010, 2016) allows for few generalisations, especially in methodological and content-wise terms. Reductionist approaches to education may try to conceptualise, analyse or even dissect its particular narratives, its nature and characteristics, but, generally speaking, studying the phenomenology of such an intersectional field renders a complex picture made up of different trends, epistemological standpoints, pedagogical beliefs, and socio-cultural influences.

Yet, the European Higher Educatio Area (EHEA) may be said to be a true attempt to unify and strengthen the European higher education domain. The Sorbonne Declaration (1998) reflected a segmented Europe and aimed at a number of structural reforms seeking comparability, mobility, and recognition. However, the latest ministerial meeting held in Yerevan in 2015 speaks primarily of EHEA's duty towards employability and enhancing the quality and relevance of learning and teaching. This should be done through "pedagogical innovation in student-centred learning environments" that exploit "the benefits of digital technologies for learning and teaching" (Yerevan Communiqué, 2015:2).

The institutional framework in which the European third level education is embedded is adamant about the pedagogical and methodological approach EHEA expects: a postpositivist scenario where 'education' becomes 'learning' (Biesta, 2013a, 2013b), conceived almost exclusively in student-centred, constructivist terms.

The shift in the mainstream educational paradigm from a traditional empirico-rationalist model (Doll, 2002; Kiraly, 2016) towards constructivist premises does have methodological implications. Indeed, knowledge acquisition is understood as an activity that has little to do with acquisition and is regarded instead as a re-contextualisation of the existing cognitive structures of the self, a re-conceptualisation of the world taking place when the cognising agent, the student, faces a new situation that contradicts, widens, or modifies previous cognitive schemas.

Therefore, third level education is currently understood in student-controlled environments that are scaffolded, in Vygotskian terms, by the guiding supportive role of the lecturer. Project-based methodology (García, 2016; Kiraly, 2012; Thomas \& MacGregor, 2005), collaborative work (Martín Ruano, 2014), the use of authentic materials in the classroom (Galán Mañas, 2011; Hagemann, 2016; Kiraly, 2016), the use of new technologies (Kasa \& Heidrich, 2016), etc., become tools to shape that educational shift; a change, as the reflection goes, which is epistemologically grounded and, at the same time, institutionally promoted. 


\section{Introducing Wikipedia in the classroom}

"As a ground-breaking and interdisciplinary phenomenon", Alonso argues (2015:90), Wikipedia has attracted the attention of researchers from many fields, including Computer Science, Communication, Politics, and Language. More specifically, in the field of higher education, Biasutti and El-Deghaidy (2012:861) reflect on the use of wikis as an online didactic tool, mentioning how they can be used in collaborative activities in the construction of both 'personal' and 'collective knowledge', very much in syntony with the institutional framework above. Indeed, Wikipedia has become for many a platform to situate their teaching practices and unfold a plethora of activities that may suit the most varied fields: critical analysis of existing articles, article correction, article creation, article expansion and improvement, addition of references and multimedia content, translation of existing articles, etc. (Lerga \& Aibar, 2015).

The benefits one may extract from the exploitation of Wikipedia in the classroom address a substantial number of the so-called 'generic competences' reflected in the Tunning Project (González \& Wagenaar, 2003), aimed at adjusting third level education programmes to the common European framework: emancipation, interaction and communication abilities, writing skills, creativity, motivation, responsibility, critical and exegetic skills, research and IT-related abilities, empowerment, and autonomy, among others.

Wikimedia Foundation is well aware of the possibilities Wikipedia offers to the postpositivist classroom and thus a number of its affiliates are indeed addressing several educational projects, be it through the many specific sections within Wikipedia itself where resources and useful educational content are brought together (Lerga \& Aibar, 2015:3) or through Wikiprojects, that is, teams of users working for a common objective, including educational initiatives.

Besides, the Wikimedia Educational Portal, a wiki aimed at coordinating and spreading educational activities and projects, was created for anyone interested in using Wikipedia for educational purposes (ibid:4), linking projects from around the world as well as new initiatives, resources, etc. The portal, launched back in 2010, may serve as a coordination meeting point for educators and students with the support, resources and practical information Wikimedia offers.

\subsection{Wikipedia for translators}

It goes without saying that undergraduate students use Wikipedia widely in the course of their education (Brox, 2012; Knight \& Pryke, 2012) however criticism and skepticism it may receive from their lecturers (Jaschick, 2007). Similarly, professional translators and translators-to-be turn to Wikipedia for a number of purposes, namely conceptual information and terminological/lexicological aspects (Alonso, 2015:100). According to 
Alonso, a significant number of translators (70.6\%) report regular access to Wikipedia in the course of their professional activity (ibid:102), acknowledging, at the same time, their ability to detect the quality of articles. In contrast to that, an overwhelming majority (over 90\%) declared that they had never written, translated, or edited any content on Wikipedia (ibid:107), rendering an interesting scenario where translators claim to use a particular tool that they have little interaction with.

Thus, following the epistemological and institutional framework current third level education is embedded in, and taking into account the pedagogical possibilities that Wikipedia offers and the extensive use professional translators make of the platform, a pedagogical innovation activity was envisaged in order to enrich the educational classroom experience of translators-to-be.

\section{The Project}

\subsection{Operational framework}

The following project is the outcome of a teaching innovation programme carried out between Jaume I University and Wikimedia Spain. The project introduces a holistic methodology aimed at building a solid translation competence among translator trainees while successfully introducing them to real discursive practices, and therefore enhacing the socialisation process of the students as inter-linguistic professionals.

The project belongs to a bigger network called "Teaching Translation via Wikipedia" started by Professor María Calzada Pérez (Jaume I University -Spain-) and Professor Khaled Al-Shehari (Sultan Qaboos University -Oman-) and currently involves some thirty lecturers in countries such as Spain, the UK, Argentina, Turkey, Jordan, Algeria, etc. who are implementing similar projects sharing a common aim: the use of an authentic projectbased methodology and collaborative work in the translation classroom.

At Jaume I University there are currently four languages involved, three of them in both directions (Catalan/Spanish into English and English into Catalan/Spanish) and a fourth one, French, which is only translated into the students' mother tongue (French into Catalan/Spanish).

Translation students at Jaume I University need to undergo two reverse translation modules during their 4-year-long bachelor degree in Translation and Interpreting. These reverse translation modules are placed in the third and fourth academic years of the curriculum, so students are expected to display a number of relevant translation strategies and resources they have built during their previous training. Still, even if it shares some features with the direct translation modules (into the student's mother tongue), directionality plays a major 
role in the course and poses an added difficulty for translators-to-be, whose proficiency in their target language may not be as polished as reverse translation requires. The role of the reverse translation lecturers throughout the module is not only to scaffold their students' learning process but also to fill the linguistic voids that hinder the development of a comprehensive translation competence.

Throughout the Wikipedia project, students are encouraged to translate, in a collaborative fashion, real Wikipedia articles that, despite existing in their source language, the Wikipedia in their target language lacks. The students' work and development is carefully scaffolded by a team of external experts who have no relation with our university (Wikipedia technicians and linguistic proof-readers) whose role is to mimic a real life translation commission. The project is embedded in a constructivist scenario where the student is fully in charge of their education, and it results in an empowering learning opportunity with a real impact in life. Indeed, not only do students learn and practise throughout all the phases of the project, but at the same time their translations help expand free-of-charge collaborative knowledge, the basis of Wikipedia, which is a way to 'give back' to the community since Wikipedia is a tool they normally use but seldom support.

\subsection{Theoretical assumptions}

As we have put forward, the aim of the project is to create meaningful learning experiences based on collaborative work and authentic project-based tasks. We agree with Pagano (1994) when she argues that teacher-centred methodologies, following transmissionist pedagogical criteria, result in a significant loss in the students' motivation. In our opinion, in terms of professional education, authentic collaborative work leads not only to a better understanding of the particular linguistic and discursive structures translators face in the course of their careers but also both the critical/exegetic skills they need in order to assess the kind of texts with which they are commissioned, and the special discursive techniques associated to the translating task. In terms of education and personal growth, finding ways of relating education with professional practice is a key notion in empowerment-oriented pedagogy, something we fully agree with.

\subsection{Project realisation}

\section{Setting up the task}

During the first session, the students are introduced to Wikipedia, its aims, its working methods and how to edit and create pages in both their source and target language Wikipedia. With the assistance of a Wikipedia technician, students are invited to explore the website and become familiar with html language and other editing options Wikipedia offers to its users. After this introductory stage, students are given time to create groups and select a text to translate. In the reverse translation classrooms choosing a text may prove to 
be slightly more complicated given the size of Wikipedia in English (5 million+ articles, compared to the $500000+$ articles in the Catalan Vikipèdia and 1 million+ articles in the Spanish Wikipedia). Students are not given any guidelines so as to what text to choose, except for the word limit, around 400 words per team member: it is up to the group to assess the degree of complexity of a given text compared to their learning goals and current translation expertise. After the text selection, the students present the text to their lecturer and justify the text they have chosen in terms of context, difficulty, underlying rationale, etc. When the text proposals are accepted, the role of the lecturer ceases to be prescriptive and they become a scaffolding tool, whenever needed.

\section{$\underline{\text { Translation }}$}

Students are given four weeks to translate the text. Students need to agree on the different roles the will adopt in the project (translator, terminologist, editor, proof-reader, etc.) or even if they want to work under more collaborative premises (group translation, group editing, group proof-reading). Students are asked to translate the text and provide an identic target text including all IT-related technicalities they could come across (images, hyperlinks, formatting options, etc.).

\section{$\underline{\text { Revision }}$}

There are two revision stages after the translation phase ends: a peer review and a double external review (translation expert and Wikipedia technician). During the former, the lecturer re-assigns the texts translated among the groups, who adopt the role of a proofreader and check their classmates' translations, suggesting changes, if any. After that first stage, the groups decide whether to accept or reject their peers' suggestions, delivering a second draft of their target text, which is reviewed by a professional technician and an external translator. After the second revision stage students are given time to implement comments and suggestions and deliver their final translation, which is finally published in Wikipedia.

\section{$\underline{\text { Looking back without anger }}$}

Once the project finishes, there is an individual and group feedback session where students comment on their performance and major problems they have faced in the course of their translation/revision task. Students are asked to comment on their individual performance, group performance, working methods and the impact the project has had in the development of their translation, professional, and inter-personal skills, and also to comment on their classmates' contributions and their role as proof-readers of the other groups. 


\section{Conclusions}

The Translating Wikipedia Project has been an on-going initiative at Jaume I University since 2010. So far, more than 400 students have taken part in the project, making it a successful initiative to implement in our translation modules. At the end of the course, students consistenly believe their command and knowledge about Wikipedia is better, they have grown as professional translators and they have developed a very interesting set of competences and skills to be applied in a rich multi-lingual number of contexts (MartínezCarrasco, in press). Similiarly, the facilitators (lecturers, Wikipedia technicians and external translators) report high levels of satisfaction and acknowledge better overall results in the education process of the students.

\section{References}

Alonso, E. (2015). Analysing the use and perception of Wikipedia in the professional context of translation. The Journal of Specialised Translation, (23), 89-116. http://doi.org/10.1016/j.sbspro.2015.02.071

Biasutti, M., \& El-Deghaidy, H. (2012). Using Wiki in teacher education: Impact on knowledge management processes and student satisfaction. Computers and Education, 59(3), 861-872. http://doi.org/10.1016/j.compedu.2012.04.009

Biesta, G. (2013a). Interrupting the Politics of Learning. Power and Education, 5(1), 4.

Biesta, G. (2013b). Receiving the gift of teaching: From "learning from" to "being taught by." Studies in Philosophy and Education, 32(5), 449-461.

Brox, H. (2012). The Elephant in the Room: a Place for Wikipedia in Higher Education. Nordlit, (30), 143-155.

Doll, W. E. (2002). Ghosts and the Curriculum. In W. E. Doll \& N. Gough (Eds.), Curriculum Visions. New York: Peter Lang.

EHEA Ministerial Conference, M. (2015). Yerevan Communiqué.

Galán Mañas, A. (2011). Translating authentic technical documents in specialised translation classes. JoSTrans, (16), 109-125.

García, C. (2016). Project-based Learning in Virtual Groups - Collaboration and Learning Outcomes in a Virtual Training Course for Teachers. Procedia - Social and Behavioral Sciences, 228 (June), 100-105.

González, J., \& Wagenaar, R. (2003). Tuning. Final Report. Bilbao.

Hagemann, S. (2016). (Non-)Professional, Authentic Projects? Why Terminology Matters. In Towards Authentic Experiential Learning in Translator Education (pp. 33-52). Mainz: V\&R Press. 
Jaschick, S. (2007). A stand against Wikipedia. Inside Higher Education, (26). Retrieved from https://www.insidehighered.com/news/2007/01/26/wiki

Kasa, R., \& Heidrich, B. (2016). Knowledge generation and utilization in wiki supported teamwork - An experiment. In 2nd International Conference on Higher Education Advances, HEAd'16 (pp. 261-268). Valencia.

Kiraly, D. (2012). Growing a Project-Based Translation Pedagogy: A Fractal Perspective. Meta: Journal Des Traducteurs, 57(1), 82. http://doi.org/10.7202/1012742ar

Kiraly, D. (2016). Towards Authentic Experiential Learning in Translator Education. Mainz: V\&R Press

Knight, C., \& Pryke, S. (2012). Wikipedia and the University, a case study. Teaching in Higher Education, 17(6), 649-659.

Lerga, M., \& Aibar, E. (2015). Best Practice Guide to Use Wikipedia in University Education. Universitat Oberta de Catalunya UOC. Retrieved from http://hdl.handle.net/10609/41662

Martín Ruano, M. del R. (2014). From Suspicion to Collaboration: Defining New Epistemologies of Reflexive Practice for Legal Translation and Interpreting. Jostrans, The Specialised Translation Journal, (22), 1-20.

Martínez-Carrasco, R. (in press). Collaborative Writing 2.0 Socialising Critical, Crosscultural Agents through Online, Project-based Methodology. Cross-Cultural Perspectives on Technology-Enhanced Language Learning. Hershey: IGI Global

Risku, H. (2010). A cognitive scientific view on technical communication and translation: Do embodiment and situatedness really make a difference? Target, 22(1), 94-111. http://doi.org/10.1075/target.22.1.06ris

Risku, H. (2016). Situated learning in translation research training: academic research as a reflection of practice. The Interpreter and Translator Trainer, 417(May), 1-17. http://doi.org/10.1080/1750399X.2016.1154340

Thomas, W. R., \& MacGregor, S. K. (2005). Online project-based learning: How collaborative strategies and problem solving processes impact performance. Journal of Interactive Learning Research, 16(1), 35-39. 